\title{
Indications of density-dependent effects from comparisons of sperm whale populations
}

\author{
Benjamin Kahn, Hal Whitehead, Mary Dillon* \\ Biology Department, Dalhousie University, Halifax, Nova Scotia, Canada B3H 4J1
}

\begin{abstract}
Standardized studies of living sperm whales Physeter macrocephalus were carried out in 3 areas with very different recent whaling intensities. These were off the Galápagos Islands, where there seems to have been little recent whaling, off the Seychelles and Amirantes Islands, where animals were regularly caught by passing Soviet whalers, and off mainland Ecuador, adjacent to the area whaled very heavily from Paita, Peru. Sperm whale densities off the Galápagos were about 4.2 times higher than off the Seychelles and 2.4 times higher than off mainland Ecuador. Feeding success, as indicated by defecation rates, was significantly higher off the Seychelles than in the other 2 areas. Calving rates showed the same trend, but differences between areas were not significant. Length distributions of females and immatures were similar off the Galápagos and Seychelles but rather larger animals were found off mainland Ecuador. There were very low densities of large, mature males in all areas. Our results, with the exception of the low feeding success and calving rate found off mainland Ecuador, are consistent with general models of density-dependent processes. The discrepancies may be due to migration of whales to mainland Ecuador from less exploited regions.
\end{abstract}

\section{INTRODUCTION}

To manage and conserve whale stocks, information about the effects of whaling on the behaviour of individual whales and thus on the population parameters of whale populations is of particular importance. With the cessation of most whaling operations during the last $10 \mathrm{yr}$, there is special interest in the medium-term (ca 2 to $20 \mathrm{yr}$ ) effects of whaling on the recovery of depleted whale populations. In general we would expect density-dependent effects to operate. The reduction in population caused by whaling operations should increase the availability of food per individual and thus improve fecundity, survival and/or growth (e.g. Fowler 1984). These changes, in turn, lead to population regeneration.

Whaling can potentially affect whale behaviour and population dynamics in other ways (Fowler 1984). During the last $40 \mathrm{yr}$ whaling for sperm whales

\footnotetext{
- Addressee for correspondence
}

Physeter macrocephalus has concentrated on mature males, changing the adult sex ratio in some areas (e.g. Clarke et al. 1980). It has been suggested that this may have resulted in a disruption of the sperm whales' mating system, leading to a reduction in pregnancy rates, and thus lessening the potential of the population for recovery (Clarke et al. 1980, May \& Beddington 1980. Whitehead 1987).

Best (1980) found an increase in sperm whale birth rates during the development of the whaling industry off Durban, South Africa, and Kasuya (1991) showed that, as exploitation progressed, there were changes in the length distributions of males, but not females, in the North Pacific. These and other studies of densitydependence in sperm whale populations have examined changes in population parameters during the course of exploitation. However, because of nonlinearity in the degree to which density-dependent effects are expressed, the most important changes in large whale population parameters are likely to occur at population levels close to carrying capacity (Fowler 1984). This means that studies of exploited 
populations cannot usually expose the full magnitude of density-dependent effects.

Using techniques of studying living sperm whales developed during the 1980's (Whitehead \& Gordon 1986) comparative studies of exploited and unexploited populations can now be made. Such studies can potentially be compromised by differing ecological conditions or migration between populations. However, if these problems are considered, then carefully controlled comparative research on populations with different exploitation histories may be able to indicate the existence and importance of different densitydependent effects.

In this paper we compare measures of sperm whale density, feeding success, calving rate, and the relative abundance of mature males, as well as length distribution, between sperm whale populations in 3 areas (off the Galápagos Islands, Seychelles and Amirantes Islands, and mainland Ecuador) which have had very different recent exploitation histories.

\section{MATERIALS AND METHODS}

Field studies were carried out off the Galápagos Islands $\left(2^{\circ} \mathrm{S}\right.$ to $1^{\circ} \mathrm{N}, 89$ to $\left.93^{\circ} \mathrm{W}\right)$ in February-April 1985, January-June 1987, May 1988, April-May 1989. and March-April 1991; off the Seychelles and Amirantes Islands ( 2 to $8^{\circ} \mathrm{S}, 51$ to $57^{\circ} \mathrm{E}$ ) in February-May 1990 , and of mainland Ecuador $\left(3^{\circ} \mathrm{S}\right.$ to $2^{\circ} \mathrm{N}$, 80 to $83^{\circ} \mathrm{W}$ ) in January-March 1991 (Fig. 1). Off the Galápagos none of the measures considered in this paper, except adult male abundance, showed substantial seasonal variation. We used 10 to $18 \mathrm{~m}$ auxiliary sailing vessels which spent 10 to $25 \mathrm{~d}$ at sea between

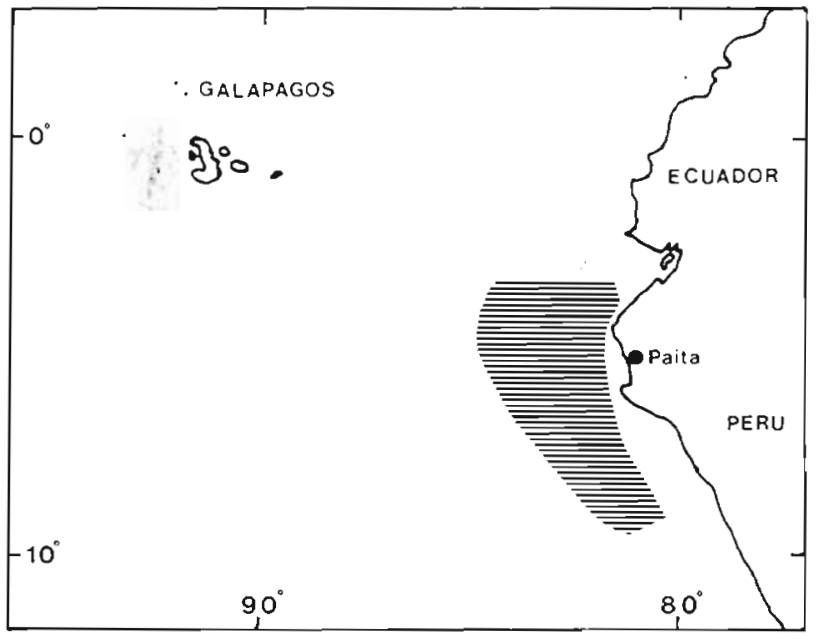

Fig. 1 Geographical relationships between Galápagos and mainland Ecuador study areas (shaded) and Paita whaling grounds (hatched; from Ramirez 1989)

port calls. Whales were located and tracked both acoustically, using a directional hydrophone, and visually for continuous periods of days (Whitehead \& Gordon 1986). The great majority of the time was spent tracking groups of females and immatures, although these were sometimes accompanied by mature males.

The mean time spent searching for whales was used as a rough indicator of the abundance of aggregations of whales (Table 1). Standard errors for mean search times were estimated using negative exponential distribution theory, and differences between the rates of finding sperm whales in the different areas were tested using the likelihood-ratio ' $G$ ' test.

During the 1985 and 1987 Galápagos studies, and the research off mainland Ecuador, we recorded the

Table 1 Physeter macrocephalus. Estimates of sperm whale population parameters (with estimated SE) for 3 study areas

\begin{tabular}{|c|c|c|c|}
\hline Parameter & Galápagos & Seychelles & Mainland Ecuador \\
\hline Aggregation size (whales) & $\begin{array}{l}43.1 \\
(3.9)\end{array}$ & $\begin{array}{c}9.4 \\
(1.2)\end{array}$ & $\begin{array}{l}30.7 \\
(5.3)\end{array}$ \\
\hline Search time (h) & $\begin{array}{l}27.5 \\
(3.5)\end{array}$ & $\begin{array}{l}25.4 \\
(6.4)\end{array}$ & $\begin{array}{c}47.2 \\
(15.7)\end{array}$ \\
\hline $\begin{array}{l}\text { Whale density index } \\
\left.\text { (whales } h^{-1}\right)\end{array}$ & 1.57 & 0.37 & 0.65 \\
\hline Calves/Females & $\begin{array}{c}0.040 \\
(0.009)\end{array}$ & $\begin{array}{c}0.089 \\
(0.053)\end{array}$ & $\begin{array}{c}0.019 \\
(0.001)^{\mathrm{a}}\end{array}$ \\
\hline Males/Females & 0.013 & 0.006 & 0.011 \\
\hline Defecation rate (defecations $f l u k e^{-1}$ ) & $\begin{array}{c}0.062 \\
(0.014)\end{array}$ & $\begin{array}{c}0.156 \\
(0.023)\end{array}$ & $\begin{array}{c}0.058 \\
(0.002)^{a}\end{array}$ \\
\hline \multicolumn{4}{|l|}{ Length distribution: } \\
\hline No of estimates & 1002 & 79 & 346 \\
\hline $\operatorname{Mean}(\mathrm{m})$ & 9.3 & 9.5 & 10.1 \\
\hline $\mathrm{SD}(\mathrm{m})$ & 0.8 & 0.6 & 0.9 \\
\hline
\end{tabular}


underwater sounds of the sperm whales on a regular schedule (Whitehead \& Kahn 1992). Recordings were made less regularly off the Seychelles. Sperm whales make trains of regularly spaced clicks about $0.5 \mathrm{~s}$ apart much of the time they are under water. Using estimates of the proportion of time an individual sperm whale spends clicking (Whitehead \& Weilgart 1990, Whitehead \& Kahn 1992), we were able to convert the measured click rates during these recordings into estimates of the number of whales within acoustic range of our hydrophone, the 'aggregation size'. Although acoustic range will depend somewhat on oceanographic conditions, rough estimates of the range in the different ocean areas are quite consistent at about 5 to $7 \mathrm{~km}$. Series of click rate estimates from the different studies were edited to remove autocorrelation, as described by Whitehead \& Kahn (1992), so that standard errors of these aggregation sizes could be estimated, and statistical tests of differences between aggregation sizes in the different areas could be performed.

Dividing the estimated mean aggregation size by the mean search time, we obtained a 'whale density index' for each area which should be roughly proportional to average whale density in the study area during the study period.

During daylight we approached clusters of sperm whales discreetly to photograph their flukes (tails) as they dived. We use fluke photographs to identify individual whales (Arnbom 1987). For each cluster from which we took fluke photographs, we recorded the number of first-year calves present, the number of large (>12 $\mathrm{m}$ in length) adult males present and the number of other whales (termed 'females' in this paper for brevity, although some immature males are included in this category). For each study area, if $F$ is the total number of females recorded, $C$ the total number of first-year calves, and $M$ the total number of large males, then $C / F$ and $M / F$ are used as indicators of the relative incidence of calves and adult males.

As a measure of overall feeding success, for all areas we use the proportion of photographed fluke-ups during which a defecation was observed. Defecations are often seen when sperm whales perform vigorous aerial activity, such as leaps from the water, but the rate at which they defecate when fluking-up seems to be most related to feeding success (Whitehead et al. 1989a). This measure of defecation rate is slightly different from that used by Whitehead et al. (1989a). The difference is due to the different data collection methods on the different surveys and the need to standardize methods over the studies.

In order to compare calving and defecation rates for the different areas, they were calculated separately for each calendar month of the 1985, 1987 and 1989
Galápagos studies, the Seychelles study, and the mainland Ecuador study and in total for the shorter 1988 and 1991 Galápagos studies. These allowed us to estimate approximate standard errors for the measures and to test for differences between the mean rates for the different areas using ANOVA, whose assumptions the data (when suitably transformed) appeared to meet. Months in which less than $100 \mathrm{fe}-$ males were observed were omitted from the calving rate analysis.

During the 1985 and 1987 Galápagos studies, and the Seychelles and the mainland Ecuador studies, sperm whales were measured by taking a photograph from a position 9 to $11 \mathrm{~m}$ above the sea surface, which included the whale approximately parallel to the horizon, and with its snout, blowhole and dorsal fin visible above the surface. Knowing the height of the camera, its focal length and the relationships between different dimensions on sperm whales, the lengths of the sperm whales can be estimated from such photographs using the methods of Gordon (1990) and Waters \& Whitehead (1990). As in Waters \& Whitehead's (1990) study, errors were minimized by not using this technique in conditions with substantial swells and excluding from the analysis photographs where the angle between the whale and the horizon was greater than $30^{\circ}$. Estimates of length from different photographs of the same whale (as noted by distinctive marks on the animal or the whale's position in relation to the horizon, wave-direction, clouds or other whales) taken within 5 min of one another were averaged. However, as it is usually impossible to identify individuals from measuring photographs over longer periods, there are unknown numbers of duplicate measurements of the same whale in the data sets. Hence no statistical tests were carried out on these data. Length estimates from. mature males and first-year calves were omitted from. subsequent analysis.

\section{RESULTS}

\section{Density}

Mean sperm whale densities were about 2.5 times higher off the Galápagos than mainland Ecuador, and about 4 times higher off the Galápagos than the Seychelles (Table 1) (Kahn 1991). These differences are largely due to the smaller aggregation sizes off the Seychelles, and the longer search times of mainland Ecuador. The differences in mean aggregation sizes of the different areas is clearly highly significant (Kruskal-Wallis, $p<0.001$ ), whereas differences between the rates of finding sperm whales in the 3 study areas were not ( $G=2.96,2 \mathrm{df}, \mathrm{p}>0.1)$. 


\section{Calving rate}

Calving rates appear to have been much higher off the Seychelles than in the other 2 areas (Table 1). The estimated standard error of the calving rate in the mainland Ecuador study area, 0.001, should be viewed cautiously, as it is based on only 2 mo of data which happened to have similar measures of calving rates. The standard deviation of the Galápagos data (0.030) would be a more realistic estimate of the standard error of the estimated mean for mainland Ecuador. There is, however, no significant difference between the calving rates in the different areas (ANOVA using arcsine-squareroot transformation to stabilize variances, $F_{2,14}=1.30, \mathrm{p}=0.30$ ).

\section{Adult males}

Adult male densities were low in all 3 areas (Table 1). We do not present standard errors for means, or tests for differences between areas, because off the Galápagos the density of mature males showed considerable seasonal variation (Whitehead et al. 1989b), seasons of study differed for the 3 areas, and mating seasons, when the males are presumably most abundant, also vary between geographic areas (Best et al. 1984). Our measure of male density was 0.0265 off the Galápagos in April and May, which we believe to be the primary breeding season, and 0.0072 during the other months in which we conducted studies.

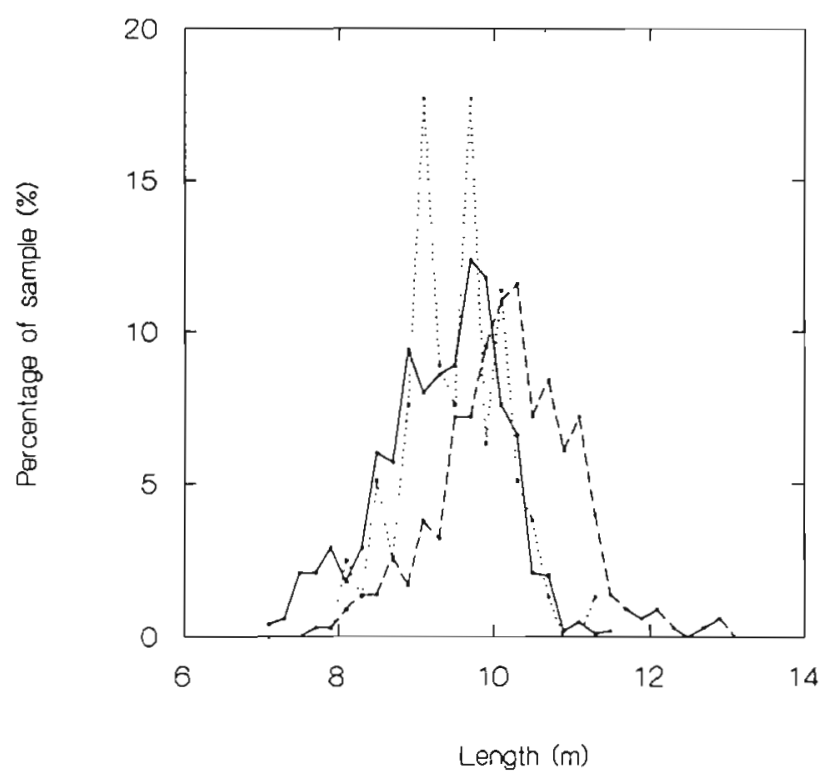

Fig. 2. Physeter macrocephalus. Length distributions for Galápagos ( - ) mainland Ecuador $(--\cdots-$, and Seychelles $(\ldots .$.$) sperm whale populations$

\section{Defecation rate}

Defecation rates were ca 2.5 times higher off the Seychelles than in the other 2 areas, which had similar defecation rates (Table 1). There was a significant difference between the monthly defecation rates in the 3 areas $\left(F_{2,15}=5.54, \mathrm{p}=0.016\right)$.

\section{Length distribution}

There were substantial differences among the length distributions from the 3 areas with the Ecuador whales averaging about $0.5 \mathrm{~m}$ larger (Fig. 2). Length distributions for the Galápagos and Seychelles were very similar (Table 1, Fig. 2; Kahn 1991). The Ecuador length distribution was quite similar to that of the whales caught at Paita, Peru, between 1959 and 1961 during the earlier period of whaling there (Fig. 3; Clarke et al. 1968), but between 1976 and 1981 whales were generally smaller (Ramirez 1989).

\section{DISCUSSION}

Two principal density-dependent effects of population reduction due to whaling have been proposed for sperm whales. These are illustrated in Fig. 4. In the standard process, exploitation in the past has reduced the current population density below the carrying capacity of the environment. This either leaves more food

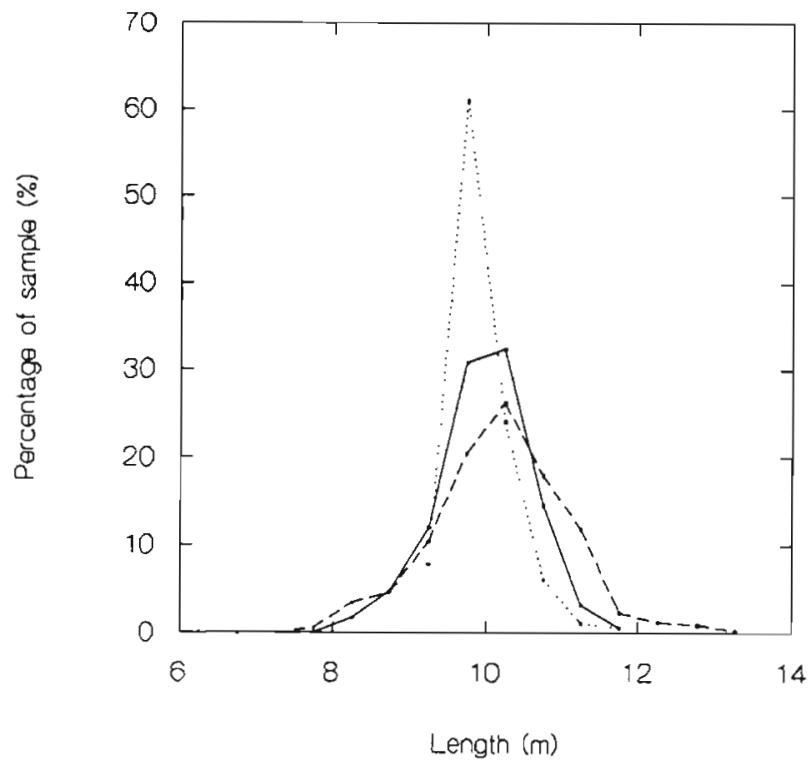

Fig. 3. Physeter macrocephalus. Comparison of sperm whate length distributions for Paita, Peru, between 1959-1961,

(—; Clarke et al. 1968), 1976-1981 (…..; Ramirez 1989) and off mainland Ecuador in $1991(\ldots \ldots-)$ 


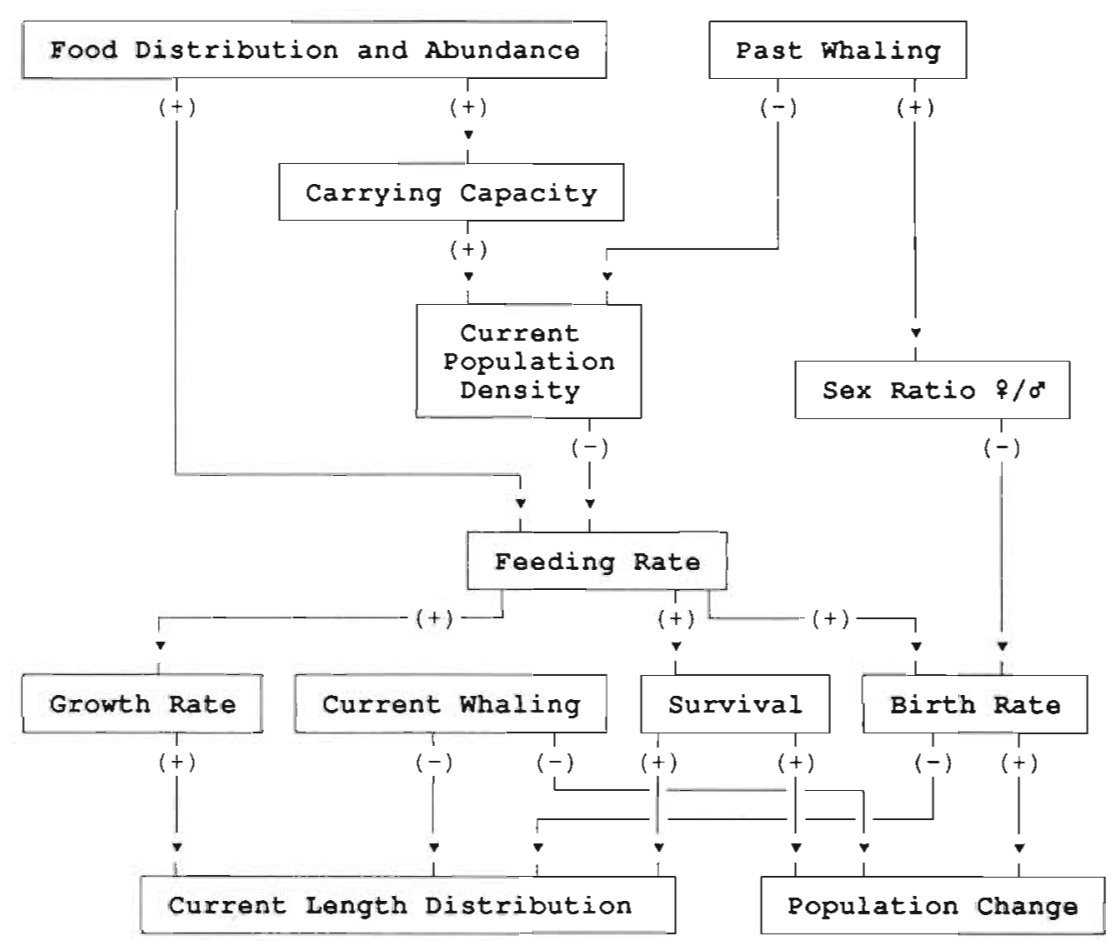

Fig. 4. Some of the major relationships which may produce density-dependent effects in sperm whale populations. $(+)$ indicates a relationship in which an increase in the value of the upper measure will tend to increase the value of the lower one; $(-)$ indicates a relationship in which an increase in the value of the upper measure will tend to decrease the value of the lower one those subject to the substantial fishery conducted from Paita, Peru, until 1983. During the 1991 study, groups were followed from the waters off mainland Ecuador into the Peruvian whaling grounds (Fig. 1). The data clearly show that this fishery substantially reduced the stock (Ramirez 1989). In contrast, we know of no evidence of whaling during the 20th century off the Galápagos. The 2 areas are separated by about $1000 \mathrm{~km}$, and, although sperm whales occasionally travel between the 2 regions, our individual identification data show the stocks to be largely distinct (Ivashin 1978, S. Dufault \& H. Whitehead unpubl.). In most years between the early 1950's and 1979 . Soviet whalers took numbers of sperm whales in the Seychelles/ Amirantes area on their way to the Antarctic (Bureau of International Whaling Statistics Reports summarized by Kahn 1991). It is also possible that the Seychelles whales may be part of a migratory population whose habitat includes the for each whale (scramble competition) or decreases interference when feeding (interference competition) resulting in increased feeding success per individual. This increased feeding success may improve fecundity, survival and/or growth, leading to population increase, as well as potentially affecting the length distribution (Fig. 4). In addition, changes in the adult sex ratio, caused by selective whaling for mature males, has been suggested as a reason for low or declining birth rates (Clarke et al. 1980, Whitehead 1987).

Mesopelagic and bathypelagic squid are particularly hard to catch, so there are no good direct measures of the distribution and abundance of sperm whale food. However, over broad scales, sperm whale distributions mirror those of primary production (Gulland 1975). Primary production off the Galápagos and mainland Ecuador seems to average 90 to $180 \mathrm{~g} \mathrm{C} \mathrm{m}^{-2} \mathrm{yr}^{-1}$ (Berger 1989), although, as much of the sperm whale research off the Galápagos was carried out in the upwelling plume of the Cromwell Current just west of the islands (Houvenaghel 1978), the mean productivity in the waters off the Galápagos where data were collected may have been generally rather higher than this. Off the Seychelles the yearly average is about $55 \mathrm{~g} \mathrm{C} \mathrm{m}^{-2} \mathrm{yr}^{-1}$ (Wyrtki 1971).

The whales off mainland Ecuador were presumably waters off Durban, South Africa where substantial sperm whaling took place until 1975. Thus the recent catch history of the Seychelles population is probably intermediate between the apparent unexploited state of the Galápagos and the heavy exploitation off mainland Ecuador/Peru.

These comparisons between the primary productivities and catch histories of the 3 areas suggest that the current whale density off the Galápagos should be higher than that off either mainland Ecuador or the Seychelles. Our results show this (Table 1), and are consistent with both primary productivity and recent whaling pressure off the Seychelles and Ecuador/Peru affecting density. In particular, the low sperm whale density off the Seychelles may be due to the accumulative effects of low primary productivity and recent whaling (Kahn 1991).

The model summarized in Fig. 4 predicts higher defecation rates, as indicators of feeding success, for the recently exploited Seychelles and mainland Ecuador study areas, compared with the whales off the Galápagos. Defecation rates were substantially, and significantly, higher off the Seychelles but not so off mainland Ecuador.

Of the 2 potential mechanisms for changes in fecundity outlined in Fig. 4, our results support the tradi- 
tional density-dependent mechanism of reduced fecundity with decreased feeding success: calving rates, although showing no significant difference between areas, are positively associated with defecation rates (Table 1). This does not necessarily rule out scarcities of males reducing pregnancies, and thus calving rates. Both mature males and calves were rarely sighted in all 3 studies.

Changes in length distributions are harder to predict and interpret. It might be expected that densitydependent processes would lead to larger sizes in exploited populations, as found by Kasuya (1991) for male sperm whales of the North Pacific. However, during heavy exploitation there is likely to be a decrease in the proportion of large whales as the mean age of the population declines. This will be exacerbated if there is selection by the whalers for larger sized whales.

The change in length distribution off mainland Ecuador and Peru indicated in Fig. 3 is consistent with that which might be expected during a period of heavy exploitation (Fig. 4). During 1976-1981, following $20 \mathrm{yr}$ of exploitation there were fewer older females at or near physical maturity in the population than in the 1959-1961 sample towards the beginning of exploitation. But, by 1991, 8 yr after the end of whaling, the population contained a substantial number of females near asymptotic length, restoring the original length distribution. That female lengths did not appear to rise significantly over the course of exploitation is in agreement with Kasuya's (1991) conclusions from his analysis of length distributions of female sperm whales of the North Pacific during the course of exploitation. If density-dependent effects are most important at population levels close to carrying capacity (Fowler 1984), an increase in size due to greater food availability might not be observed during much of the course of exploitation (Kasuya 1991) or in the years immediately following it.

However, unexploited populations would be expected to be made up of generally smaller animals than those recovering from exploitation. The whales currently off the Galápagos do appear to be smaller than those in the same area between 1830 and 1850 during the Yankee whaling period (Hope \& Whitehead 1991), and those in the exploited population off mainland Ecuador (Fig. 2). Although these results would seem to argue for density-dependent changes in female lengths during the initial phases of exploitation, the low defecation rate of mainland Ecuador appears not to be consistent with this. The small sizes found off the Seychelles could be partially due to geographic variation, as females from different oceans seem to differ in size (Clarke et al. 1968).

Thus our results generally support the model out- lined in Fig. 4, and especially are consistent with the links between sperm whale density and ocean productivity, sperm whale density and whaling intensity, as well as to that between feeding success and birth rate. The major apparent inconsistency is in the low defecation rates and calving rates estimated for the mainland Ecuador area where the population would appear to have been considerably reduced by whaling. That calving rates were also low in this area argues against the poor feeding success being a temporary aberration of the period of our study. A possible explanation for these effects is that migrants from the Galápagos and other parts of the Pacific have colonized the mainland Ecuador area since the end of whaling, so that the population density there now might be substantially increased over that during the closing period of whaling operations. However, the differing length distributions for the Galápagos and Ecuador study areas argue against substantial migration.

Acknowledgements. The funding organizations of the 1985 and 1987 Galápagos studies, as well as those who collected and analyzed the data, are acknowledged by Waters \& Whitehead (1990). The Seychelles study was partially funded by the Cetacean Society International and sponsored by Canadian Airlines International and Kodak Canada. The 1988, 1989 and 1991 Galápagos studies and mainland Ecuador study were funded by the Natural Sciences and Engineering Research Council of Canada with assistance from the Whale and Dolphin Conservation Society and Ilford Canada. We are most grateful to those who collected the data at sea: M. Barbeau, S. Brennan, A. Faucher, G. Faure, M Friedl, K. Gonzalves, N. Jaquet, Y James, M. Jones, Y Lelengboto, K. Lohr, G. Merlen, H. Reyes, K. Richard, T. du Roy, T Schleman, R. Smith, S. C. Smith and S. Waters. We thank the Armada of Ecuador and the government of the Republic of the Seychelles for permission to carry out the research, H. G. Kahn who made his sailboat available for the Seychelles study, G. Merlen, N. Shah and the Charles Darwin Foundation for considerable assistance, and $\mathrm{Y}$. James, $\mathrm{P}$ McKenna, S. C. Smith, S. Waters and L. Weilgart for their parts in the analysis. S. Dufault and 3 anonymous reviewers usefully reviewed the manuscript.

\section{LITERATURE CITED}

Arnbom, T (1987). Individual identification of sperm whales. Rep. int. Whal. Commn 37: 201-204

Berger, W. H. (1989). Global maps of ocean productivity. In: Berger, W. H., Smetacek, $V$ S., Wefer, G. (eds.) Productivity of the ocean: present and past. John Wiley, New York, p. 429-455

Best, P. B. (1980). Pregnancy rates in sperm whales off Durban. Rep. int. Whal. Commn (spec. issue 2): 93-97

Best, P. B., Canham, P. A. S., MacLeod, N. (1984). Patterns of reproduction in sperm whales. Physeter macrocephalus. Rep. int. Whal. Commn (spec. issue 6): 51-79

Clarke, R., Aguayo, A., Paliza, O. (1968). Sperm whales of the southeast Pacific. Part I: introduction. Part II: size range, external characters and teeth. Norsk Hvalfangsttid. 53: $297-302$ 
Clarke, R., Aguayo, A., Paliza, O. (1980). Pregnancy rates of sperm whales in the southeast Pacific between 1959 and 1962 and a comparison with those from Paita, Peru between 1975 and 1977 Rep. int. Whal. Commn (spec. issue 2): $151-158$

Fowler, C. W. (1984). Density dependence in cetacean populations. Rep. int. Whal. Commn (spec. issue 6): 373-379

Gordon, J. C. D. (1990). A simple photographic technique for measuring the length of whales from boats at sea. Rep. int. Whal. Commn 40: 581-588

Gulland, J. A. (1975). Distribution and abundance of whales in relation to basic productivity. In: Schevill, W. E. (ed.) The whale problem. Harvard Univ. Press, Cambridge, p. 27-52

Hope, P. L., Whitehead, H. (1991) Sperm whales off the Galápagos Islands 1830-50 and comparisons with modern studies. Rep. int. Whal. Commn 41: 273-283

Houvenaghel, G. T (1978). Oceanographic conditions in the Galápagos Archipelago and their relationships with life on the islands. In: Boje, R., Tomczak, M. (eds.). Upwelling ecosystems. Springer Verlag, New York, p. 181-200

Ivashin, M. V. (1978). Soviet investigations of cetacea, June 1976 to May 1977. Rep. int. Whal. Commn 28: 119-122

Kahn, B. (1991). The population biology and social organization of sperm whales (Physeter macrocephalus) of the Seychelles: indications of recent exploitation. M.Sc. thesis, Dalhousie University, Halifax

Kasuya, T (1991). Density-dependent growth in North Pacific sperm whales. Mar. Mammal Sci, 7: 230-257

May, R. M., Beddington, J. R. (1980). The effect of adult sex

This article was submitted to the editor ratio and density on the fecundity of sperm whales. Rep int. Whal. Commn (spec. issue 2): 213-217

Ramirez, P. (1989). Captura de cachalote en Paita: 1976-1981 Boletin de Lima 63: 81-88

Waters, S., Whitehead, H. (1990). Population and growth parameters of Galápagos sperm whales estimated from length distributions. Rep. int. Whal. Commn 40 $225-235$

Whitehead, H. (1987). Social organization of sperm whales off the Galápagos: 1mplications for management and conservation. Rep. int. Whal. Commn 37: 195-199

Whitehead, H., Gordon, J (1986). Methods of obtaining data for assessing and modelling sperm whale populations which do not depend on catches. Rep. int. Whal. Commn (spec. issue 8): 149-166

Whitehead, H., Kahn, B. (1992). Temporal and geographical variation in the social structure of female sperm whales. Can J. Zool. 70: 2145-2149

Whitehead, H., Papastavrou, V., Smith, S. (1989a). Feeding success of sperm whales and sea-surface temperatures off the Galápagos Islands. Mar. Ecol. Prog. Ser. 53: 201-203

Whitehead, H., Weilgart, L. (1990). Click rates from sperm whales. J. Acoust. Soc. Am. 87: 1798-1806

Whitehead, H., Weilgart, L., Waters, S. (1989b). Seasonality of sperm whales off the Galápagos Islands, Ecuador. Rep. int. Whal. Commn 41: 207-210.

Wyrtki, K. (1971). Oceanographic atlas of the international Indian Ocean Expedition. National Science Foundation, Washington, DC

Manuscript first received: April 24, 1992

Revised version accepted: December 19, 1992 